\title{
MASS CALIBRATION AND RELATIVE HUMIDITY COMPENSATION REQUIREMENTS FOR OPTICAL PORTABLE PARTICULATE MATTER MONITORS: THE IMPASHS (IMPACT OF SMOKE-FREE POLICIES IN EU MEMBER STATES) WP2 PRELIMINARY RESULTS
}

\author{
Ruprecht $A A^{1,2}$, De Marco $C^{1}$, Boffi $R^{1}$, Mazza $R^{1}$, Lopez $M J^{3}$, Moshammer $H^{4}$, \\ Dautzenberg $B^{5}$, Clancy $L^{6}$, Precioso $J^{7}$, \& Invernizzi $G^{1,2}$ \\ ${ }^{1}$ Fondazione IRCCS Istituto Nazionale Tumori di Milan Italy, ${ }^{2}$ SIMG-Società Italiana \\ di Medicina Generale Italy, ${ }^{3}$ Agencia de Salut Publica de Barcelona Spain, ${ }^{4}$ Medical \\ University of Vienna Austria, ${ }^{5}$ OFT Paris France, ${ }^{6}$ Research Institute for a Tobacco \\ Free Society Dublin, Ireland, ${ }^{7}$ Instituto de Educação e Psicologia. Universidade do \\ Minho, Braga, Portugal. \\ info@tecanalysis.it
}

\begin{abstract}
Introduction

Better knowledge of particulate matter (PM) concentrations needs portable, reliable, user friendly, low cost, real time mass analyzers of PM2.5 and PM10.

Optical Particle Counters (OPC) measuring mass have manufacturer calibration specific gravity " $\mathrm{K}$ " factor referred to polystyrene latex particles which are completely different than those of the real world, therefore they require specific calibrations. Measurements are also subject to Relative Humidity (RH) heavy interference.
\end{abstract}

\section{Objectives}

To evaluate, within the IMPASHS WP2 Project, the performance of four different OPC's in Environmental Tobacco Smoke and background urban pollution and to find the new " $\mathrm{K}$ " factors using one Model BAM-1020 with certificate n. EPQM0798-122 for comparison.

\section{Methodology}

All instruments have been operating in parallel measuring PM2.5 generated by cigarettes (ETS) indoor and by urban pollution outdoor and the data were replicated three times.

\section{Results}

“ $K$ ” factors were widely different between manufacturer's model, instrument serial numbers, ETS and urban pollution, ranging from 0.5 to 2.27. Correlation with BAM-1020 was ranging from 0.7500 to 0.9800 and Student $t$ test from 0.3000 to 0.9500 . Relative Humidity interference resulted mathematically compensable up to $75 \% \mathrm{RH}$, but above becomes uncontrollable and sample drying becomes compulsory. 


\section{Conclusion}

OPC's are very reliable and accurate but need specific calibration and special care in handling and elaboration of the measurements.

\section{Introduction}

Measurement of indoor/outdoor particulate matter (PM) pollution in real time can be satisfactorily and reliably performed using Optical Particle Counters (OPC), if properly calibrated according to the procedure described in the next paragraphs. The OPC's principle of operation is the nephelometric measurement based on the light scattering of airborne particles. The sample of air is normally drawn into the light scattering sensor (nephelometer) with a flow controlled rotary vane pump. The nephelometer is constituted by a light source (low power laser diode), scattered light collection optics and a photo detector circuit. The flow path for the air crosses the path of the laser diode. When the air is clean (absence of airborne particulate), the laser diode light is extinguished in a light trap, but when the air is containing airborne particulate, there is scattering of light which is collected and measured.

The output signals from the detector are empirically proportional to the number and size of particles and are elaborated to present the data expressed in number of particles per liter of selected classes of diameters.

However the certified particulate matter measurement systems are based on gravimetric methods and the concentrations are expressed in micrograms per cubic meter $\left(\mu \mathrm{g} / \mathrm{m}^{3}\right)$ therefore it is necessary to convert the number of particles per liter to mass. Unfortunately all light scattering devices have inherent difficulties when converting light scatters to mass. Index of refraction and mean particle diameter can affect the amount of light scattered from the same amount of mass ${ }^{6}$. A mathematical equation is applied to the number/size of particles measured by the OPC to obtain first the particle total volume on which a " $\mathrm{K}$ " factor is applied to adjust for the specific gravity of the PM to be measured. The simplest solution is to compare the OPC's mass measurements made with default factory " $K "=1.000$ for a set period of time with the mass measured by a gravimetric system over the same period of time. Comparing the concentrations will yield a "K" that can be applied to all OPC measurements performed by the same calibrated analyzer. 
Another factor which greatly influences the mass measurements of the OPC's is the interference of the relative humidity (RH). Sioutas et al. in 2000, and Chakrabarti et al. in 2004 showed that RH could drastically affect the mass concentrations measurements of one OPC model as demonstrated in Fig. 1 in which the desired concentration ratio is 1 and, at $\mathrm{RH}$ values greater than $50 \%$, this ratio begins to increase due to particle aggregation (particle size increase as water is absorbed).

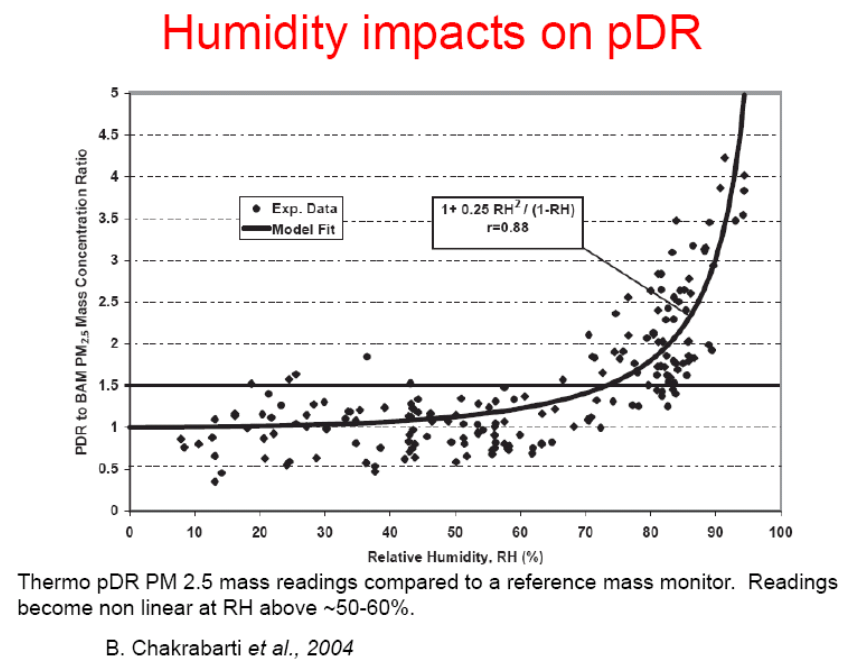

Fig. 1

To prevent this inaccuracy it is necessary to provide the OPC measurements with a simultaneous RH measurements and compensate mathematically. However above 80/85 $\% \mathrm{RH}$, the interference become so high that inaccuracy in $\mathrm{RH}$ measurements brings to unacceptable errors in the concentrations. To obviate to this errors and to permit the use of OPC's also when RH is greater than $80 \%$ it become necessary to reduce the RH to the light scatter chamber to about $50 \%$ either by heating the sample or by drying it by means of permapure dryer ${ }^{\mathrm{TM}}$.

\section{Objectives}

To evaluate, within the IMPASHS WP2 Project, the performance of four different OPC's in the measurements of Environmental Tobacco Smoke (ETS) and background urban pollution and to find the new " $\mathrm{K}$ " factors for $\mathrm{PM}_{2.5}$ using as automatic mass reference the measurements of one Model BAM-1020 with certificate of equivalence 


\section{Methodology}

The method to measure PM environmental pollution used in monitoring stations all over the world is the gravimetric (Federal Reference Method FRM or the European equivalent) and the data are generally presented as mass of $\mathrm{PM}_{2.5}$ and $\mathrm{PM}_{10}$. The system consists of equipment designed to accumulate the PM on a pre-weighted filter through which a known air flow is sampled for a programmable time. At the end of the sampling time the filter is removed and accurately dried and weighted. The difference in weight is the amount of PM deposited on the filter which, divided for the number of cubic meters of air passed through the filter, gives the mass expressed in micrograms per cubic meter $\left(\mu \mathrm{g} / \mathrm{m}^{3}\right)$. However this method requires skilled operators and expensive laboratory equipment, is time consuming and deliver the results of the measurements only with a delay of some days. To overcome this inconvenient, automatic sampling and measurement methods have been developed which can deliver the concentrations every 1 or 2 hour's. These methods are the Beta Attenuation Monitors (BAM) and Tampered Element Oscillating Balance (TEOM). Several manufacturers have developed analyzers based on these principles of operation and many have been designed as equivalent to the gravimetric by the U.S.A. Environmental Protection Agency. These analyzers are commonly used in most of the monitoring stations and deliver the concentrations in hourly averages informing in almost real time the pollution level. The $\mathrm{PM}_{2.5}$ measurements of the OPC models described in Appendix A are compared with the same $\mathrm{PM}_{2.5}$ measured by one Beta Attenuation Monitor model BAM-1020, equipped with standard $\mathrm{PM}_{2.5}$ inlet. The BAM-1020, is manufactured by Metone Instruments Inc. and is designated as equivalent method by U.S. E.P.A. n. ${ }^{\circ}$ EQPM-0798-122 and certified by the German T.Ü.V. (: 936/21205333/A Köln, 06.12.2006).

Site informations: the generation of ETS aerosol and the measurements have been performed in the Tobacco Control Unit Research Laboratory of the Fondazione IRCCS Istituto Nazionale dei Tumori, located in Milan, in a room of about $45 \mathrm{~m}^{3}$ without air conditioning and with about 0.3/0.4 air exchange per hours (ach). To assure the maximum mixing factor (PM concentrations of the same value in every point of the room), one fan of about $1,500 \mathrm{~m}^{3} /$ hour was always in operation during the ETS generation and measurements. 


\section{Results}

\section{RH Interference compensation}

During all tests the $\mathrm{RH}$ was measured and all raw data have been mathematically compensated according the Sioutas tests using the following equation:

$C_{\text {comp }}=C_{\text {meas }} /((1+(R H / 100) 7) \times 3.72)$

Where: $\quad C_{\text {comp }}=$ concentration compensated for $\mathrm{RH}$ interference

$$
C_{\text {meas }}=\text { concentration measured }
$$

$\boldsymbol{R H}=$ Relative Humidity measured

Fig. 2 shows the interference compensation curve and Fig. 3 the linear regression analysis.

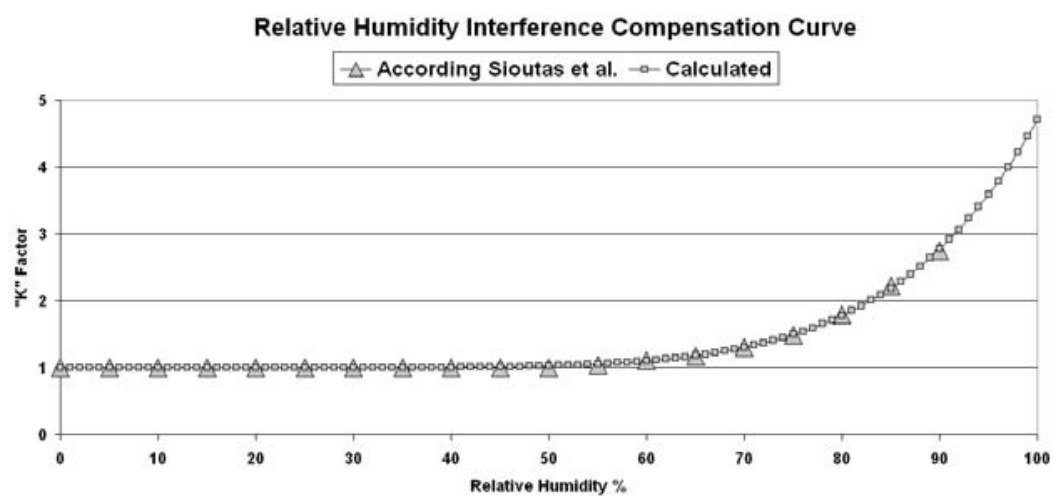

Fig. 2

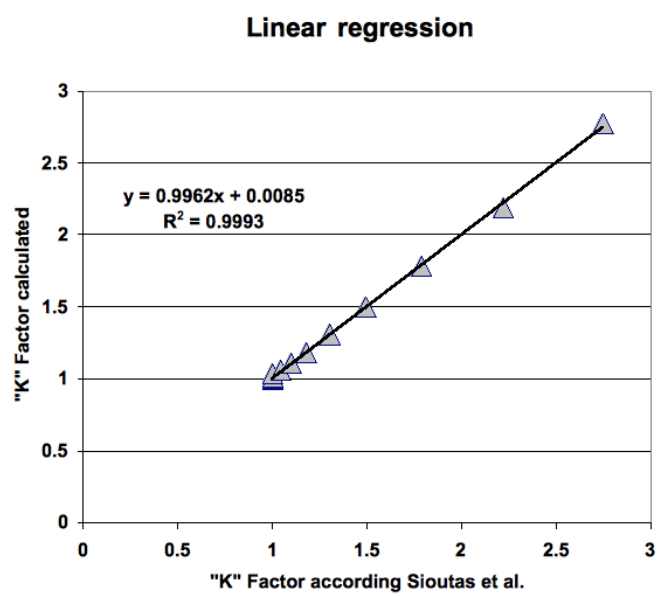

Fig. 3 
The accuracy of the RH interference correction using the above equation has been experimentally tested measuring continuously the outdoor $\mathrm{PM}_{2.5}$ concentrations over a wintertime period for 7 days using two OPC's: the model e-sampler and the model Aerocet 531 (same instruments used for the gravimetric calibrations) operating in parallel.

The e-sampler is normally equipped with a sampler heater control system driven by a $\mathrm{RH}$ sensor installed on the inlet of the laser chamber and the RH set point is programmable. In this case the RH set point was set at $40 \%$. The Aerocet is equipped only with a Temperature and RH measurement.

The results are represented in Fig. 4: the RH changed from a minimum of about 30 to a maximum of $98 \%$ with no interference on the e-sampler indications (red line) but heavily interfering with the Aerocet 531 indication by increasing the value of a factor of 3 with $\mathrm{RH}>80 / 85 \%$. The thin black line is showing the uncorrected Aerocet 531 measurements. When the equation was applied, in excel, to the Aerocet 531 raw data, the correction was very effective. Correlation analysis and Student $t$ test between esampler and Aerocet 531 indicate the accuracy of the correction giving the following results:

Without correction: $\quad$ correlation $=0.8511$ and $p=7.7 \mathrm{E}-49$

After correction: $\quad$ correlation $=0.9765$ and $p=0.6859$

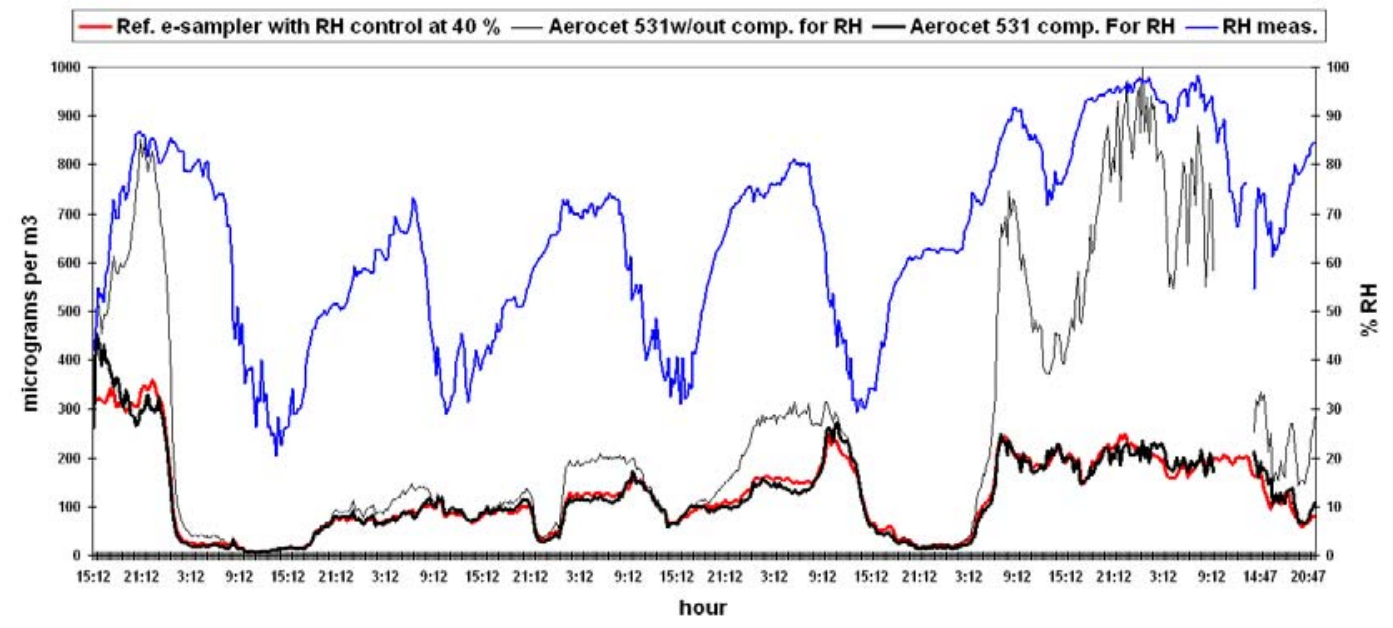

Fig. 4 


\section{“K” factor corrections}

All Analyzer measurements were made using the default " $\mathrm{K}$ " factor of 1.000 and the comparison yields to the results listed below for each instrument. Comparison is made on a hourly basis since the BAM-1020 supply the data as the average. This operation was made in Excel calculating the hourly average of the Analyzers with their internal clock synchronized with the BAM-1020 clock before starting the sampling. For each set of data, the correlation and the " $\mathrm{p}$ " of Student $\mathrm{t}$ test is calculated and reported to evaluate the accuracy and precision of the new "K" factor resulting from the calibration.

An example of the graphs and the regression analysis is shown in Fig. 5 and 6:

TEST ETS N. ${ }^{\circ} 2$

$\neg-$ E-sampler $1 \mathrm{~h}$ ave $\leftrightharpoons$ BAM-1020 $1 \mathrm{~h}$ ave

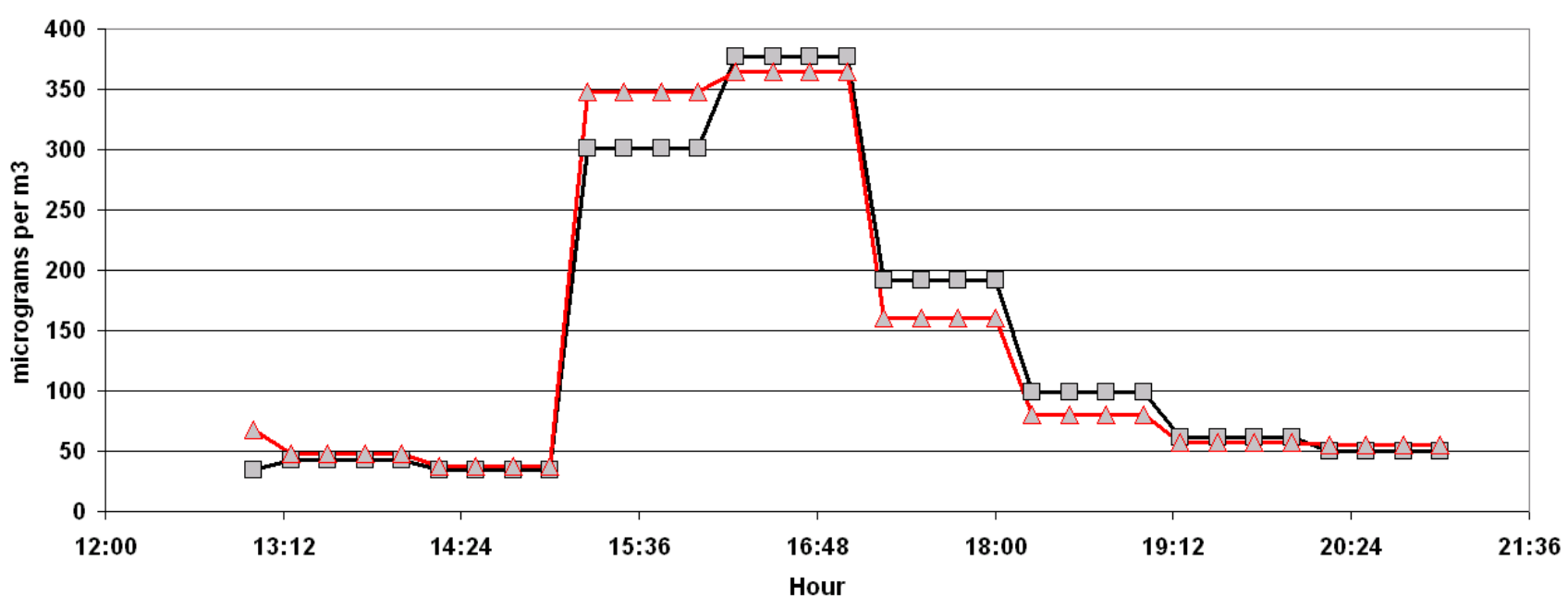

Fig. 5 
ESAMPLER/BAM-1020 TEST N. ${ }^{\circ} 2$

REGRESSION ANALYSIS

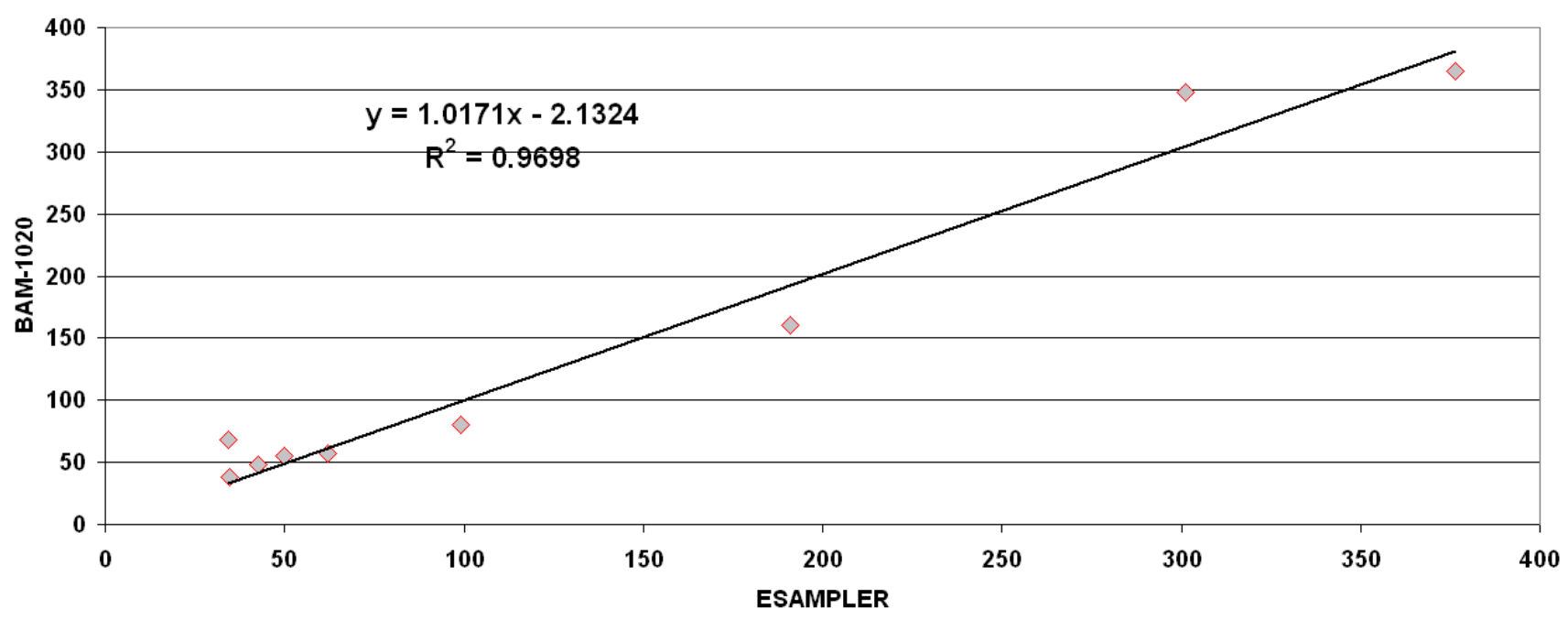

Fig. 6

The following tables show the detailed results for each test and each OPC.

1.- Model Aerocet 531, Metone Instruments Inc. serial \# E-1871

Tobacco Control Unit, National Cancer Institute, Milan, Italy

\begin{tabular}{|c|c|c|c|c|c|}
\hline III $^{\circ}$ test & BAM & Aerocet & Correlation & P test & K factor \\
\hline ETS & 128.0 & 129.2 & 0.9147 & 0.2361 & 11.5 \\
\hline URBAN & 49.0 & 49.0 & 0.7943 & 0.9769 & 8.1 \\
\hline II $^{\circ}$ test & BAM & Aerocet & Correlation & P test & K factor \\
\hline ETS & 179.8 & 179.8 & 0.9940 & 0.9767 & 10.2 \\
\hline URBAN & 57.3 & 57.4 & 0.8574 & 0.7661 & 14.3 \\
\hline$I^{\circ}$ test & BAM & Aerocet & Correlation & P test & K factor \\
\hline ETS & 201.5 & 201.6 & 0.9912 & 0.9478 & 12.2 \\
\hline URBAN & 52.0 & 52.0 & 0.9032 & 0.9871 & 16.9 \\
\hline Average & Correlation & P test & K factor (SD) & & \\
\hline ETS & 0.9666 & 0.7202 & $11.3(1.0)$ & & \\
\hline URBAN & 0.8516 & 0.9100 & $13.1(4.5)$ & & \\
\hline
\end{tabular}


2.- Model Aerocet 531, Metone Instruments Inc. serial \# 8551

Research Institute for a Tobacco Free Society, Dublin, Ireland

\begin{tabular}{|l|l|l|l|l|l|}
\hline III ${ }^{\circ}$ test & BAM & Aerocet & Correlation & P test & K factor \\
\hline URBAN & 189.1 & 186.8 & 0.9821 & 0.9310 & 10.2 \\
\hline II $^{\circ}$ test & 18.9 & 19.0 & 0.9665 & 0.5470 & 6.6 \\
\hline ETS & BAM & Aerocet & Correlation & P test & K factor \\
\hline URBAN & na & 133.4 & 0.9915 & 0.7079 & 8.1 \\
\hline I $^{\circ}$ test & BAM & Aerocet & Correlation & P test & Ka factor \\
\hline ETS & 86.3 & 86.6 & 0.9871 & 0.8629 & 9.2 \\
\hline URBAN & na & na & na & na & na \\
\hline Average & Correlation & P test & K factor (SD) & & \\
ETS & 0.9869 & 0.8340 & $\mathbf{8 . 1}(\mathbf{1 . 0 5})$ & & \\
\hline URBAN & na & na & $\mathbf{6 . 6}($ na) & & \\
\hline
\end{tabular}


3.- Model Aerocet 531, Metone Instruments Inc. serial \# F-8557

OFT, Paris, France

\begin{tabular}{|l|l|l|l|l|l|}
\hline III ${ }^{\circ}$ test & BAM & Aerocet & Correlation & P test & K factor \\
\hline URBAN & 189.1 & 189.1 & 0.9818 & 0.1924 & 8.3 \\
\hline II $^{\circ}$ test & 18.9 & 18.9 & 0.9777 & 0.8638 & 5.5 \\
\hline ETS & BAM & Aerocet & Correlation & P test & K factor \\
\hline URBAN & na & 109.3 & 0.9904 & 0.9278 & 6.3 \\
\hline$I^{\circ}$ test & BAM & Aerocet & Correlation & P test & Ka factor \\
\hline ETS & 86.3 & 86.7 & 0.9974 & 0.5606 & 7.0 \\
\hline URBAN & na & na & na & na & na \\
\hline Average & Correlation & P test & K factor (SD) & & \\
ETS & 0.9899 & 0.5603 & $\mathbf{8 . 1}(\mathbf{1 . 0 1})$ & & \\
\hline URBAN & na & na & $\mathbf{5 . 5}($ na) & & \\
\hline
\end{tabular}


4.- Model 1.180 Portable Aerosol Spectrometer, Grimm serial\#8F070042

Inst. Umwelthygiene, ZPH, Wien, Austria

\begin{tabular}{|l|l|l|l|l|l|}
\hline$I^{\circ}$ test & BAM & Grimm & Correlation & P test & K factor \\
\hline ETS & 253.3 & 253.0 & 0.9990 & 0.9625 & 1.26 \\
\hline URBAN & 51.7 & 51.5 & 0.8423 & 0.6725 & 1.30 \\
\hline II ${ }^{\circ}$ test & BAM & Grimm & Correlation & P test & K factor \\
\hline URBAN & 198.2 & 199.2 & 0.9781 & 0.9468 & 1.22 \\
\hline III ${ }^{\circ}$ test & 56.9 & 54.4 & 0.9733 & 0.4936 & 1.30 \\
\hline ETS & BAM & Grimm & Correlation & P test & K factor \\
\hline URBAN & 151.6 & 152.7 & 0.9969 & 0.7579 & 1.10 \\
\cline { 1 - 3 } & 49.6 & 49.6 & 0.9391 & 0.9308 & 1.26 \\
\hline ETS & Correlation & $\mathbf{p}$ test & K Factor (SD) & & \\
\hline URBAN & 0.9914 & 0.8890 & $\mathbf{1 . 2 ( 0 . 0 8 )}$ & & \\
\hline
\end{tabular}


5.- Model SidePak TSI Serial\# 10805037

Servei d'Avaluaciò i Metodes d'Intervenciò

Agencia de Salut Publica de Barcelona, Barcelona, Spain

\begin{tabular}{|l|l|l|l|l|l|}
\hline III $^{\circ}$ test & BAM & S. 10805037 & Correlation & P test & K factor \\
\hline ETS & 135.8 & 134.7 & 0.9980 & 0.7397 & 0.45 \\
\hline URBAN & 49.1 & 49.1 & 0.9304 & 0.9763 & 0.51 \\
\hline II $^{\circ}$ test & BAM & S. 10805037 & Correlation & P test & K factor \\
\hline ETS & 198.2 & 49.1 & 0.9304 & 0.9763 & 0.51 \\
\hline URBAN & 58.0 & 57.6 & 0.9756 & 0.6299 & 0.47 \\
\hline$I^{\circ}$ test & BAM & $\mathbf{S . ~ 1 0 8 0 5 0 3 7}$ & Correlation & P test & K factor \\
\hline ETS & 196.5 & 196.3 & 0.9947 & 0.9880 & 0.56 \\
\hline URBAN & 52.8 & 52.8 & 0.8990 & 0.9700 & 0.52 \\
\hline Average & Correlation & P test & K factor (SD) & & \\
\hline ETS & 0.9744 & 0.9013 & $\mathbf{0 . 5 1}(\mathbf{0 . 0 5})$ & & \\
\hline URBAN & 0.9350 & 0.8587 & $\mathbf{0 . 5 0}(\mathbf{0 . 0 2})$ & & \\
\hline
\end{tabular}


6.- Model SidePak TSI Serial\# 10805044

Servei d'Avaluaciò i Metodes d'Intervenciò

Agencia de Salut Publica de Barcelona, Barcelona, Spain

\begin{tabular}{|l|ll|ll|l|}
\hline III $^{\circ}$ test & BAM & S. 10805044 & Correlation & P test & K factor \\
\hline ETS & 135.8 & 135.9 & 0.9981 & 0.9727 & 0.45 \\
\hline URBAN & 49.1 & 49.5 & 0.9263 & 0.6171 & 0.48 \\
\hline II $^{\circ}$ test & BAM & S. 10805044 & Correlation & P test & K factor \\
\hline ETS & 157.6 & 157.2 & 0.9884 & 0.9677 & 0.52 \\
\hline URBAN & 47.2 & 47.6 & 0.3453 & 0.6901 & 0.48 \\
\hline$I^{\circ}$ test & BAM & S. 10805044 & Correlation & P test & K factor \\
\hline ETS & 176.0 & 174.9 & 0.9955 & 0.9020 & 0.55 \\
\hline URBAN & 52.7 & 52.4 & 0.9184 & 0.8267 & 0.55 \\
\cline { 1 - 3 } & Correlation & P test & K factor (SD) & & \\
\hline ETS & 0.9940 & 0.9475 & $\mathbf{0 . 5 1}(\mathbf{0 . 0 5})$ & & \\
\hline URBAN & 0.7300 & 0.7113 & $\mathbf{0 . 5 0}(\mathbf{0 . 0 4})$ & & \\
\hline
\end{tabular}


7.- Model e-sampler, Metone Instruments Inc. serial \# G3427

Tobacco Control Unit, National Cancer Institute,Milan, Italy

\begin{tabular}{|c|c|c|c|c|c|}
\hline III $^{\circ}$ test & BAM & e-sampler & Correlation & P test & K factor \\
\hline ETS & 224.0 & 224.6 & 0.8621 & 0.4453 & 1.77 \\
\hline URBAN & 52.4 & 52.0 & 0.9659 & 0.4390 & 1.85 \\
\hline II $^{\circ}$ test & BAM & e-sampler & Correlation & P test & K factor \\
\hline ETS & 141.6 & 141.3 & 0.9884 & 0.9070 & 1.77 \\
\hline URBAN & 56.9 & 56.6 & 0.9884 & 0.9070 & 1.66 \\
\hline$I^{\circ}$ test & BAM & e-sampler & Correlation & P test & K factor \\
\hline ETS & 123.3 & 124.2 & 0.9568 & 0.5634 & 1.51 \\
\hline URBAN & 49.2 & 49.1 & 0.9568 & 0.8593 & 1.24 \\
\hline Average & Correlation & $P$ test & K factor (SD) & & \\
\hline ETS & 0.9358 & 0.6385 & $1.68(0.1)$ & & \\
\hline URBAN & 0.9704 & 0.7351 & $1.58(0.3)$ & & \\
\hline
\end{tabular}

Summary of "K" factors

\begin{tabular}{|l|l|l|l|l|l|l|l|}
\hline & Aerocet & Aerocet & Aerocet & Grimm & SidePak & SidePak & e-sampler \\
& 1 & $\# \mathbf{2}$ & $\# \mathbf{3}$ & $\# \mathbf{4}$ & $\# \mathbf{5}$ & $\# \mathbf{6}$ & $\# \mathbf{7}$ \\
\hline ETS & $11.3(1.0)$ & $8.1(1.05)$ & $8.1(1.01)$ & $1.2(0.08)$ & $0.51(0.05)$ & $0.51(0.05)$ & $1.68(0.1)$ \\
\hline URBAN & $13.1(4.5)$ & $6.6 \mathrm{na}$ & $5.5 \mathrm{na}$ & $1.3(0.02)$ & $0.50(0.02)$ & $0.50(0.04)$ & $1.58(0.3)$ \\
\hline
\end{tabular}

\section{Comments}

"K" factors were found to vary noticeably not only between manufacturer's model but also between instruments of the same manufacturer with different serial numbers.

Differences in the " $\mathrm{K}$ " factors between ETS and urban pollution have also been found and must be taken in consideration during the measurements campaigns. 
Long term measurements in urban pollution ( 7 days) showed changes in the optimal "K" factor suggesting that there may be changes in urban pollution composition affecting it sensibly, but the evaluation of the amount of these changes needs more investigations.

These facts are confirming the very well known phenomena of optical characteristics modifications caused by changes in the physical/chemical composition and morphology of the PM.

These factors together with the modification in specific gravity are consequently changing the final mass measurement whenever the typology of PM is changing.

In the test conditions, the " $\mathrm{K}$ " factors were ranging from 0.5 to 13.1. But despite this wide range, the accuracy and precision for a given typology of PM measured with all OPC's compared with the BAM-1020 measurements were good, ranging from about 0.3500 to 0.9800 and Student $t$ test from about 0.3000 to 0.9500 . Also the repeatability of the measurements of all analyzers when used with the same PM characteristics is acceptable.

\section{Conclusion}

All OPC's can be considered suitable for the measurements of ETS PM provided the above "K" factors are applied to the raw data. Regarding urban pollution it must be advised that there may be differences in case the physical/chemical composition and morphology of the PM of the site where the measurements are made differs from those of Milan, where the calibration have been made. In this case it is suggested to proceed locally with a further calibration to determine the new factor.

Relative Humidity interference can be compensated mathematically and with acceptable accuracy up to $80 / 85 \% \mathrm{RH}$, but above these values the error introduced by the $\mathrm{RH}$ measurement (normally $\pm 5 \% \mathrm{RH}$ ) becomes unacceptable and sample drying becomes compulsory.

OPC's are extremely simple and user friendly to use, maybe too simple: just push a button and they go and in a few minutes they produce the data. They are also very reliable and accurate. But the correct interpretation of the data is not so simple; manufacturer factory calibration data cannot be applied and they absolutely need 
specific calibration and special care in handling and elaboration of the measurements applying the procedures above described.

\section{References}

1.- Repace JL, Lowrey AH. Indoor air pollution, tobacco smoke and public health. Science

$1980 ; 208: 464-72$

2.- Invernizzi G., Ruprecht A.A., De Marco C., Mazza R., Rossetti E., Boffi R.. Realtime measurement of indoor particulate matter originating from environmental tobacco smoke: a pilot study. Epidemiol Prev 2002;26:30-4.

3.- Boffi R., Ruprecht A.A., Mazza R., Ketzel M., Invernizzi G.. A day at the European Respiratory Society Congress: passive smoking influences both outdoor and indoor air quality. Eur Resp. J, 2005, 4: 862-863.

4.- Repace J. Measurements of outdoor air pollution from secondhand smoke on the UMBC campus. http://www.repace.com/pdf/outdoorair.pdf. Date last accessed: December 2005. Date last updated: November 2005.

5.- Invernizzi G. Ruprecht A.A., De Marco C., Mazza R., Lopez M. J., Gorini G., Boffi R... Outdoor Environmental Tobacco Smoke: its contribution to outdoor ambient pollution in a selected area of the historical city center of Milan. In publication

6.- Jenkins R.A.,Ilgner R.H.,Tomkins B.A., Peters D.W. . Development and Application of Protocols for the Determination of Response of Real-Time Particle Monitors to Common Indoor Aerosols Air \& Waste Manage. Assoc. 2004 54:229-241

7.- Chung, A.; Chang, D.P.Y.; Kleeman, M.J.; Perry, K.D.; Cahill, T.A.; Dutcher, D....; Stroud, K. Comparison of Real-Time Instruments Used to Monitor Airborne Particulate Matter; J. Air \& Waste Manage. Assoc. 2001, 51, 109-120.

8.- Ott, W.; Switzer, P.; Robinson, J. Particle Concentrations inside a Tavern before and after Prohibition of Smoking-Evaluating the Performance of an Indoor Air-Quality Model; J. Air \& Waste Manage. Assoc. 1996, 46, 1120-1134. 
9.- Long, C.M.; Suh, H.H.; Koutrakis, P. Characterization of Indoor Particle Sources Using Continuous Mass and Size Monitors; J. Air \& Waste Management Assoc. 2000, $50,1236-1250$.

10.- Klepeis, N.E.; Ott, W.R.; Repace, J.L. The Effect of Cigar Smoking on Indoor Levels and Particles; J. Expos. Anal. Environ. Epidemiol. 1999, 9, 622-635.

11.- Ramachandran, G.; Adgate, J.L.; Hill, N.; Sexton, K.; Pratt, G.C.; Bock, D. Comparison of Short-Term Variations (15-Minute Averages) in Outdoor and Indoor PM2.5 Concentrations; J. Air \& Waste Manage. Assoc. 2000, 50, 1157-1166.

12.- Nelson, P.R.; Conrad, F.W. Sensitivity Correction for Portable Particulate Monitors for Environmental Tobacco Smoke. Presented at the American Association for Aerosol 13. Ogden, M.W.; Heavner, D.L.; Foster, T.L.; Maiolo, K.C.; Cash, S.L.;Richardson, J.D... Nelson, P.R. Personal Monitoring System for Measuring Environmental Tobacco Smoke Exposure; Environ. Technol. 1996, 17, 239-250.

14.- Conner, J.M.; Oldaker, G.B., III; Murphy, J.J. Method for Assessing the Contribution of Environmental Tobacco Smoke to Respirable Suspended Particles in Indoor Environments; Environ. Technol. 1990, 11,189-196.

15.- Ogden, M.W.; Maiolo, K.C.; Oldaker, G.B., III; Conrad, F.W. Evaluation of Methods for Estimating the Contribution of ETS to Respirable Suspended Particles. In Indoor Air '90, Proceedings of the 5th International Conference on Indoor Air Quality and Climate, 2; Toronto, Ontario, Canada, July 29-August 3, 1990; pp 415-420.

16.- Jenkins, R.A.; Palausky, A.; Counts, R.W.; Bayne, C.K.; Dindal, A.B; Guerin, M.R. Exposure to Environmental Tobacco Smoke in Sixteen Cities in the United States as Determined by Personal Breathing Zone Sampling; J. Expos. Anal. Environ. Epidemiol. 1996, 6, 473-502.

17.-. Maskarinec, M.P.; Jenkins, R.A.; Counts, R.W.; Dindal, A.B. Determination of Exposure to Environmental Tobacco Smoke in Restaurant and Tavern Workers in One US City; J. Expos. Anal. Environ. Epidemiol. 2000, 10, 36-49.

18.- Becquemin, R.H.; Bertholon, G.F.; Attoui, M.; Roy, F.; Roy, M.; Dautzenberg, B.; Particle size in the smoke produced by six different types of cigarettes tobacco. Rev Mal Resp 2009; 26: e12-e18 